\title{
THE INSTRUCTIONAL DESIGN OF AN ONLINE LEARNING ENVIRONMENT (RISSC) FOR UPPER SECONDARY SCHOOL STUDENTS' RESEARCH SKILLS
}

\author{
Louise Maddens ${ }^{123}$, Fien Depaepe ${ }^{123}$, Annelies Raes ${ }^{123}$, Jan Elen ${ }^{12}$, KU Leuven \& KU Leuven \\ Campus KULAK Kortrijk1, Centre for Instructional Psychology and Technology ${ }^{2}$, ITEC, KU \\ Leuven, also at imec ${ }^{3}$, Belgium
}

\section{Summary}

In today's complex world, the acquisition of research skills is considered an important goal in (upper secondary) education. Consequently, there is a growing body of literature that recognises the value of well-designed (online) learning environments for effectively supporting the development of this complex set of skills. However, a clear consensus on how these research skills can be facilitated is currently lacking. Furthermore, interventions aiming to foster these skills are often implemented in specific domains, mostly in physics, biology and chemistry. In addition, current approaches to facilitation often refer to only a few epistemic activities related to research skills. Because of the broad and (mainly) domainspecific character of research skills, the purpose of this paper is to articulate the instructional design considerations for an online learning environment for upper secondary school students' (broad set of) research skills in a(n) (underrepresented) behavioural sciences context.

\section{Introduction}

\section{Defining research skills}

In recent decades, the importance of the acquisition of research skills has been reflected in numerous curriculum and policy documents (Departement onderwijs en vorming, 2017; OECD, 2006; Opitz et al., 2017). These research skills should enable students to address problems in research, professional practice, and daily life (Opitz et al., 2017). Because of its broad (Fischer et al., 2014) character, it is necessary here to clarify exactly what is meant by research skills in this paper. While a variety of conceptualizations have been suggested in (recent) literature (Kestens, Elen, \& Verburgh, 2016), such as scientific reasoning skills (Engelmann et al., 2016; Fischer et al., 2014; Opitz et al., 2017); scientific literacy (Norris, Phillips, \& Burns, 2014) or research methods skills (Earley, 2014), in the present study the term research skills is used, as it adequately reflects the target concept as a broad set of skills (not merely referring to reasoning, literacy or research methods skills). Throughout this paper, the term will be used to refer to the definition suggested by Fischer and colleagues (2014), labelling research skills as a set of "skills and abilities to understand how scientific knowledge 
is generated in different scientific disciplines, to evaluate the validity of science-related claims, to assess the relevance of new scientific concepts, methods, and findings, and to generate new knowledge using these concepts and methods" (Fischer et al., 2014; p.29). Fischer and colleagues (2014) refer to this definition using the term scientific reasoning skills as a $21^{\text {st }}$ century skill. In short, research skills include the knowledge and skills involved in eight scientific activities, namely: (a) problem identification, (b) questioning, (c) hypothesis generation, (d) construction and redesign of artefacts, (e) evidence generation, (f) evidence evaluation, (g) drawing conclusions and (h) communicating and scrutinizing (Fischer et al., 2014).

\section{Domain-specificity of research skills}

Recent literature highlights the importance of domain-specific knowledge when it comes to apply higher-order cognitive skills (such as skills for problem-solving, critical thinking and/or research) (Kirschner, 2017). The (mainly) domain-specific character of research skills is also underlined by Fischer and colleagues (2014) (see also Engelmann et al., 2018), arguing that the relative weights of the eight activities involved in preparing, performing and evaluating research will differ across disciplines. Fischer and colleagues (2014) argue that some aspects of research skills may be similar across domains (such as the identification of dependent and independent variables), but stress that many aspects of research skills are domain-specific (such as, for example, evidence generation). Approaches to facilitation of research skills typically focus on one specific domain (Engelmann et al., 2018; Fischer et al., 2014). In addition, it is clear that a vast majority of studies on supporting research skills focuses on specific natural sciences disciplines (OECD, 2006; Gess, Wessels, \& Blömeke, 2017; Opitz et al., 2017), while very little attention has been paid to behavioural sciences disciplines (Gess et al., 2017). Furthermore, studies on the differences of research skills between disciplines have been rare (Fischer et al., 2014).

\section{Two main questions arising from the literature}

In order to deepen our understanding of research skills, the current research project builds on two existing categories of research questions. First, questions related to the assessment (and assessment instruments) of research skills are central. Second, we take a closer look at approaches aiming to answer questions related to the support of research skills in educational contexts. Although the first type of questions is receiving considerable attention in this research project (see, for example, Maddens, Depaepe, Janssen, Raes, \& Elen, in press), this paper focusses on the latter group of questions. In this paper, the instructional design considerations for an online learning environment aiming to foster upper secondary school students' research skills (in a behavioural sciences context) are outlined. The online learning environment is called RISSC (Research In Social SCiences). 


\section{Designing the online learning environment}

\section{Preliminary remarks}

\section{Definition and relevance of instructional design}

According to the definition of Elen and Clarebout (2006 p. 1), "instructional design aims at contributing to the development of learning environments by describing the basic components of a learning environment, their interrelations and their interaction with learner characteristics". The notion learning environment encompasses both the learning task (what the learner needs to learn), as the support (elements integrated into the learning task in order to foster learning) (Elen \& Clarebout, 2006). It is argued by Elen and Clark (2006) that various elements and interactions between these elements influence learning from instruction.

As learners do not automatically engage in epistemic activities (Weinberger et al., 2005), there seems to be an agreement on the importance of well-designed (online) learning environments for effectively supporting the development of complex skills. It is argued that, if designed with caution (Seel, 2006), and if adequately used by the learners (Elen \& Clarebout, 2006), the process of complex problem solving can be substantially supported by means of multimedia programs (Elen \& Clarebout, 2006; Engelmann et al., 2016; Seel, 2006).

\section{(Online) learning environments}

As stated by Merrill, "principles of instruction can be implemented in any delivery system or using any instructional architecture" (Merrill, 2002; p.44). In addition, according to Clark (1983; p.445), "there are no learning benefits to be gained from employing any specific medium to deliver instruction”. As such, citing Cook and McDonald (2008; p.7), we believe "the argument of superiority, inferiority, or equivalence is moot. It is a far better investment of resources to investigate "what works?" in e-learning, rather than trying to justify its existence". Following this rationale, the technology versus non-technology question does not seem to be the most important one to be raised. The question does remain how to design (technology-enhanced) learning environments.

In what follows, first, the structure, the goal and the target group of the instructional design of the RISSC-environment are outlined. Second, some important theoretical principles underpinning the design decisions are described and illustrated. To conclude, some further areas in research on research skills are suggested in the concluding section.

\section{Structure, goal and target group of the RISCC learning environment}

The goal of the online learning environment (further on referred to as RISSC) is to support upper secondary school students' research skills (as defined in the conceptualization section), relying on theoretical instructional design principles (as defined in the following sections). In doing so, we focus on the support and the design of learning tasks for students in a specific behavioural sciences context, because (a) the reliance of research skills on domain-specific 
knowledge has been emphasized several times in research (Fischer et al., 2014; Engelmann et al., 2016; Kirschner, 2017; Opitz et al., 2017), and (b) a majority of (intervention) studies on the support of research skills limits the focus to scientific disciplines almost exclusively situated in the field of natural sciences. In Flanders, four different types of education are offered from the second stage of secondary education onwards. In general, secondary education (one of the four types), students can choose to enrol in a program called behavioural sciences. As a result, research into supporting research skills in a behavioural sciences context is particularly scarce. In RISSC, content is available related to each of the eight epistemic activities (Fischer et al., 2014).

\section{RISSC: theoretical considerations}

\section{Five principles}

Merrill (2002) identified five first principles that can be found in instructional design models. According to these five principles, learning is promoted (a) when learners are engaged in solving real-world problems, (b) when existing knowledge is activated as a foundation for new knowledge, (c) when new knowledge is demonstrated to the learner (ideally by means of a demonstration of the whole task, rather than by means of a list of abstract objective statements); (d) when new knowledge is applied by the learner, and (e) when new knowledge is integrated into the learner's world (Merrill, 2002; p.43). Although not all of the five principles are addressed in an equally explicit way, all five principles are (in some way) implemented in the 4C/ID model (van Merriënboer \& Kirschner, 2018). The differences between programs and principles are discussed in Merrill (2002). This model (and its relation to the first principles) is described in the next section. In addition, the implementation of the instructional design principles is illustrated by means of the RISSC-environment.

\section{Four components}

It is recommended not to base instructional design decisions on one instructional design model, but rather to evaluate and to compile elements from a variety of models (Elen \& Clarebout, 2006). A model generally known because of its aim to integrate elements from different models and theories, focusing in the first place on training domain-specific complex skills, is the 4C/ID model (van Merriënboer \& Kirschner, 2018). Roughly sketched, the 4C/ID model is built upon four crucial components: learning tasks, supportive information, parttask practice, and just-in-time information. Central assumptions related to these four components are that (a) a high variability in authentic learning tasks is needed in order to deal with the complexity of the task; (b) supportive information is provided to the students in order to help them build mental models and strategies for solving the task under study (Cook \& McDonald, 2008); (c) just-in-time (procedural) information (related to steps, procedures, facts, concepts and principles) is provided for recurrent skills, and (d) part-task practice is provided for recurrent skills that need to be automated. The "Ten steps" - related to the 4C/ID model described by van Merriënboer and Kirschner (2018) - were used as a prescriptive guideline in designing the online learning environment for the present study. The sections below discuss how the four main steps (the design of learning tasks, the design 
of supportive information, the design of procedural information and the design of part-task practice) are addressed in the RISSC.

\section{Design learning tasks}

A problem-centred approach (indicating that learning is promoted when learners are engaged in solving real-world problems), the importance of student's application of new knowledge, and the integration of this new knowledge into the learner's world by means of creation and reflection tasks are prescribed in principle 1, 4 and 5 of Merrill's (2002) first principles of instruction. This whole-task approach is also key in the 4C/ID model, where the design of (a variety of) simple-to-complex real-life based whole tasks, aiming at integrating knowledge, skills and attitudes is the core design activity of the training blueprint (van Merriënboer \& Kirschner, 2018). As such, the identification of these real-life tasks for the domain under study (research skills in behavioural sciences) appeared crucial in designing the RISSC. In RISSC, cases, (modelling) examples and tasks were selected from research in the domains of psychology, educational sciences and sociology. The complexity of the learning tasks increases with each task class, and the support decreases within each task class (Merrill, 2002; van Merriënboer \& Kirschner, 2018). By means of emphasis manipulation (van Merriënboer \& Kirschner, 2018), different sets of constituent skills are stressed in different task classes, without losing sight of the whole task. The first task class, for example, focusses on problem identification, questioning and hypothesis generation, but the tasks are integrated in several cases involving real (whole) research projects.

\section{Design supportive information}

Supportive information helps learners to carry out the non-recurrent aspects of the learning tasks related to research skills (van Merriënboer \& Kirschner, 2018). In the first principles, Merrill (2002; p.47) states that "learning is promoted if the instruction provides a structure that the learner can use to build the required organizational schema for the new knowledge". In the 4C/ID model, structural, conceptual and causal domain models are provided to the learners in order to help them reasoning in the task domain. Concerning research skills, the supportive information can differ for different epistemic activities (de Jong \& van Joolingen, 1998; Fischer et al., 2014). For the epistemic activity evidence generation, for example, experimentation hints (or SAPs (van Merriënboer \& Kirschner, 2018)) and reflection prompts can be provided, while in the epistemic activity drawing conclusions, visualizing tools and knowledge integration environments (or conceptual domain models (van Merriënboer \& Kirschner, 2018)) might be helpful (de Jong \& van Joolingen, 1998). In RISCC, the transferability of the effectivity of these support tools was always evaluated based on the domain under study (behavioural sciences). Supportive information is provided in RISSC for complex tasks such as formulating a research question, where students can consult general information on characteristics of a good research question in behavioural sciences, can consult examples or demonstrations (see principle 3, Merrill, 2002) of this general information (for example a typical research question in behavioural sciences) and can receive cognitive feedback on their own research questions (Merrill, 2002; van Merriënboer \& Kirschner, 2018). 
In doing so, learners are for example asked to critically compare and contrast their own research question with an example. The supportive information is offered by means of multimedia such as pictures, texts, and information videos, and is directly accessible during the whole learning task (de Jong \& van Joolingen, 1998). An example of supportive information can be found in Figure 1. When students click on the link "criteria for a good research question", they are guided towards an in instruction video (conceptual model).

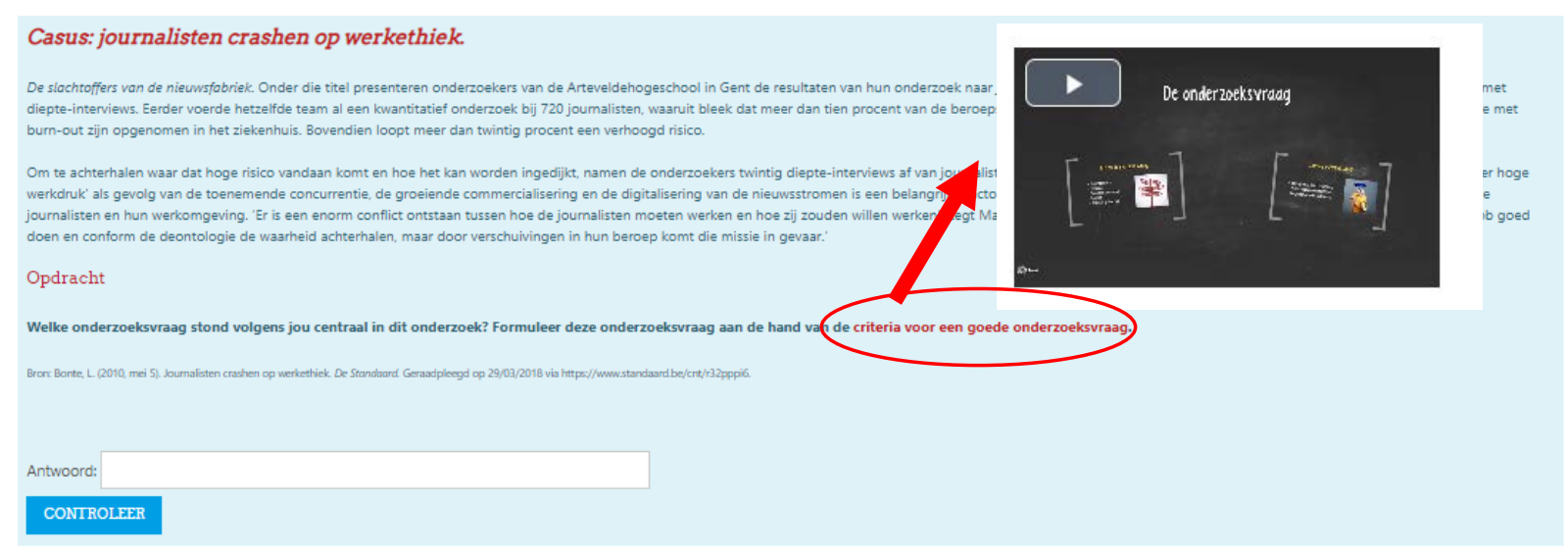

Figure 1. Example of supportive information for the non-recurrent skill "formulating a research question" in RISSC

\section{Design procedural information}

Procedural information is necessary for carrying out recurrent aspects of learning tasks (van Merriënboer \& Kirschner, 2018). As such, in RISSC, procedural information is provided for tasks such as the use of Boolean operators in a literature search, or the identification of dependent and independent variables. This information is presented just-in-time: students can consult information displays on a specific rule, procedure, fact, concept or principle (for example on the effect of the word "AND" in a search query). An example of procedural information (with procedural directions for formulating a search query) in RISSC can be found in Figure 2.

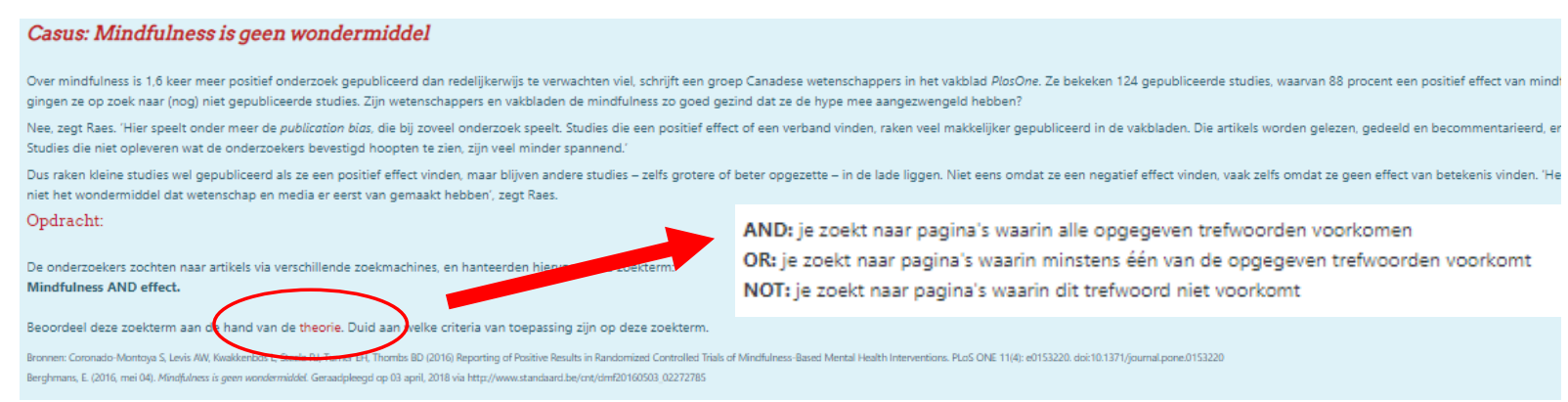

Figure 2. Example of procedural information for the Boolean operators (rules)

\section{Design part-task practice}

Part-task practice involves practice items promoting rule automation for recurrent aspects of the whole complex skill. Because an overreliance on part-task practice is not helpful for complex learning (van Merriënboer \& Kirschner, 2018), in RISSC, additional part-task 
practice is available for some (but not all) of these recurrent routine aspects of skills (for example for the formulation of a search query or the identification of dependent and independent variables). In addition, students receive corrective feedback, pointing the students to an error, and giving a hint for applying the correct rule (van Merriënboer \& Kirschner, 2018). An example of part-task practice and related corrective feedback in RISSC (for the recurrent aspect "formulating a search query") can be found in Figure 3.

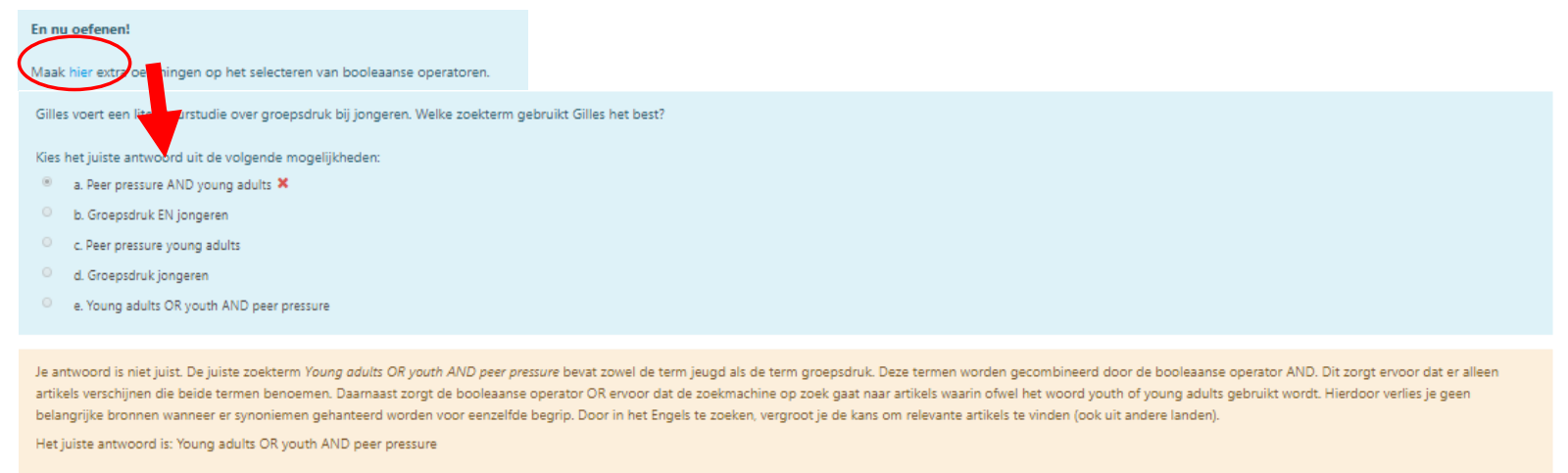

Figure 3. Example of part-task practice for the recurrent aspect "formulating a search query"

\section{Conclusion and further research}

RISSC's systematic design is based on the aforementioned insights from instructional theory, with a main focus on the 4C/ID model (van Merriënboer \& Kirschner, 2018) and the first principles of instruction (Merrill, 2002), and is unique because of its domain-specific focus on research in behavioural sciences, and its attention to eight distinct epistemic activities (Fischer et al., 2014). Although the models mentioned offer very specific guidelines, it is up to the designer to concretely operationalize these guidelines taking into account the domain under study. As such, more research is needed (and planned) into the validation of these instructional guidelines for the context of research skills in a behavioural sciences domain.

In a first planned study, the impact of two different approaches to present the learning goals in the beginning of the RISSC-environment on students' affective, behavioural and cognitive outcomes is investigated. In the first approach (also called the topic-centred approach), an abstract clarification of learning objectives is presented to the learners, while in the second approach (also called the problem-centred approach), a concrete discussion of the learning objectives is provided to the students with a concrete link to the application and integration phase. More concrete, the second approach contains a specific explication of the particular whole task the learners will perform following instruction. As such, the central question in this study is to what extent a problem-centred online learning environment influences students' affective, behavioural and cognitive learner characteristics, compared to a topiccentred online learning environment. 
The Instructional Design of an Online Learning Environment (RISSC) for Upper Secondary School Students' Research Skills

Louise Maddens et al.

\section{References}

Clark, R. E. (1983). Reconsidering research on learning from media. Review of Educational Research, 53(4), 445-459.

Cook, D. A., \& McDonald, F. S. (2008). E-learning: Is there anything special about the "e"? Perspectives in Biology and Medicine, 51(1), 5-21.

Departement Onderwijs en Vorming (2017). Secundair onderwijs - Derde graad ASO Humane wetenschappen - Specifieke eindtermen. Retrieved June 6, 2018, from http://eindtermen.vlaanderen.be

Earley, M. A. (2014). A synthesis of the literature on research methods education. Teaching in Higher Education, 19(3), 242-253. https://doi.org/10.1080/13562517.2013.860105

Elen, J., \&, Clarebout, G. (2006). The use of instructional interventons: lean learning evironments as a solution for a design problem. In J. Elen \& R. E. Clark (Eds.), Handling complexity in learning environments: Theory and Research. Oxford, G.B.: Elsevier Science Ltd.

Elen, J., \& Clark, R. E. (Eds.) (2006). Handling Complexity in Learning Environments. Theory and Research. Oxford, G.B.: Elsevier Science Ltd.

Engelmann, K., Neuhaus, B. J., \& Fischer, F. (2016). Fostering scientific reasoning in education - meta-analytic evidence from intervention studies. Educational Research and Evaluation, 22(5-6), 333-349.

Engelmann, K., Chinn, C.A., Osborne, J., \& Fischer, F. (2018). The roles of domain-specific and domain-general knowledge in scientific reasoning and argumentation. An introduction. In F. Fischer, C. A. Chinn, K. Engelmann, \& J. Osborne (Eds.), Scientific reasoning and argumentation. The roles of domain-specific and domain-general knowledge ( $1^{\text {st }}$ ed.) (pp. 1-19). London \& New York: Routledge.

Fischer, F., Chinn, C. A., Engelmann, K., \& Osborne, J. (2018). Scientific reasoning and argumentation. The roles of domain-specific and domain-general knowledge. London \& New York: Routledge.

Fischer, F., Kollar, I., Ufer, S., Sodian, B., Hussmann, H., Pekrun, R., Neuhaus, B., Dorner, B., Pankofer, S., Fischer, M., Strijbos, J-W., Heene, M., \& Eberle, J. (2014). Scientific reasoning and argumentation: Advancing an interdisciplinary research agenda in education. Frontline Learning Research, 4, 28-45.

Gess, C., Wessels, I., \& Blömeke, S. (2017). Domain-specificity of research competencies in the social sciences: Evidence from differential item functioning. Journal for Educational Research Online/Journal für Bildungsforschung Online, 9(2), 11-36.

de Jong, T., \& Van Joolingen, W. R. (1998). Scientific discovery learning with computer simulations of conceptual domains. Review of Educational Research, 68(2), 179-201. 
Kestens, J., Elen, J., \& Verburgh, A. (2016). Kritisch denken en onderzoekscompetenties: de nexus. (Unpublished master's thesis). KU Leuven.

Kirschner, P. (2017, December 21). De Holle Retoriek van '21st-Century Skills' - Hoezo is Kennis Minder Belangrijk? Blogcollectief Onderzoek Onderwijs [Blogpost]. Retrieved from https://onderzoekonderwijs.net/2017/12/21/de-holle-retoriek-van-21st-centuryskills-hoezo-is-kennis-minder-belangrijk/

Maddens, L., Depaepe, F., Janssen, R., Raes, A., \& Elen, J. (in press). Evaluating the Leuven Research Skills Test for $11^{\text {th }}$ and $12^{\text {th }}$ grade. Manuscript accepted for publication.

van Merriënboer, J. J. G., \& Kirschner, P. A. (2018). Ten steps to complex learning. New York: Routledge.

Merrill, M. D. (2002). First principles of instruction. Educational Technology Research and Development, 50(3), 43-59.

Norris, S. P., Phillips, L. M., \& Burns, D. P. (2014). Conceptions of Scientific Literacy: Identifying and Evaluating Their Programmatic Elements. In M. Matthews (Eds.), International Handbook of Research in History, Philosophy and Science Teaching (pp. 1317-1344). Dordrecht: Springer Netherlands. https://doi.org/10.1007/978-94-007-76548_40

Opitz, A., Heene, M., \& Fischer, F. (2017). Measuring scientific reasoning - a review of test instruments. Educational Research and Evaluation, 23(3-4), 78-101. https://doi.org/10.1080/13803611.2017.1338586

Organisation for Economic Co-operation and Development - OECD (2006). Assessing Scientic, Reading and Mathematical Literacy: A framework for PISA 2006. In Programme for International Student Assessment (pp. 3-125).

Seel, N. M. (2006). Mental Models and Complex Problem Solving: Instructional Effects. In J. Elen \& R. E. Clark (Eds.), Handling complexity in learning environments: Theory and Research. Oxford, G.B.: Elsevier Science Ltd.

Weinberger, A., Ertl, B., Fischer, F., \& Mandl, H. (2005). Epistemic and social scripts in computer-supported collaborative learning. Instructional Science, 33(1), 1-30.

\section{Acknowledgements}

This study was carried out within imec's Smart Education research programme, with support from the Flemish government. 